\title{
Diagnostic and Therapeutic Implications of the Vascular Endothelial Growth Factor Family in Cancer
}

\author{
Syeda Kiran Riaz ${ }^{1}$, Yasmeen Iqbal², Muhammad Faraz Arshad Malik ${ }^{1 *}$
}

\begin{abstract}
Cancer progression is attained by uncontrolled cell division and metastasis. Increase in tumor size triggers different vascular channel formation to address cell nutritional demands. These channels are responsible for transferring of nutrients and gaseous to the cancer cells. Cancer vascularization is regulated by numerous factors including vascular endothelial growth factors (VEGFs). These factors play an important role during embryonic development. Members included in this group are VEGFA, VEGFB, VEGFC,PIGF and VEGFD which markedly influence cellular growth and apoptosis. Being freely diffusible these proteins act in both autocrine and paracrine fashions. In this review, genetic characterization these molecules and their putative role in cancer staging has been elaborated. Prognostic significance of these molecules along with different stages of cancer has also been summarized. Brief outline of ongoing efforts to target hot spot target sites against these VEGFs and their cognate limitations for therapeutic implications are also highlighted.
\end{abstract}

Keywords: Metastasis - VEGF family - angiogenesis - prognosis - carcinogenesis

Asian Pac J Cancer Prev, 16 (5), 1677-1682

\section{Introduction}

Members included in this family include VEGFA, VEGFB, VEGFC, and VEGFD along with three core receptors named as VEGFR1, VEGFR2 and VEGFR3. These molecules exist in glycosylated homodimer forms and expressed on endothelial cells. These proteins are responsible for increased vascular permeability, angiogenesis, endothelial cells growth and promotion of cell migration. Interestingly, heterodimerization of these molecules receptor also stimulate vascularization (Nilsson et al., 2010). Association of these molecules with cancer are mentioned below

VEGFA: Vascular endothelial growth factor (VEGFA), also termed as vascular permeability factor (VPF) is localized on chromosome 6p12. It encodes a protein of 412 amino acids from 8 exons. Alternatively spliced transcript variants, encoding either freely secreted or cell-associated isoforms, have also been identified (Meiron et al., 2001).

VEGFB: Based on it expression in different tissues, two isoforms (VEGF-B 167 and VEGF-B 186) have been identified. VEGF-B167 isoform accounts for more than $80 \%$ of the total VEGF-B transcripts in many tissues including cardiac, skeletal muscles and neural tissues when compared with VEGF-B186 (Li et al., 2001).

VEGFC: Based on chromatography approach, localization of VEGFC on 4q34.3 region has been reported. It encodes protein of 419 amino acids from 7 exons. Increase expression has also been reported in both bronchial epithelial and smooth muscle cells.
VEGFD: Vascular endothelial growth factor D, also termed c-fos-induced growth factor (FIGF) located on Xp22.31. Abundant expression of VEGFD in fetal lung and skin tissue while lowest in skeletal muscle, colon and pancreas are detected.

VEGFE: A wide range of molecules like GM-CSF, G-CSF, IL-1b, IL-15, TNF- $\alpha$, IL-6, IL-3, LT-1 significantly regulates VEGFE expression. Interestingly, increase proangiogenic potential of VEGFE as compared to VEGFA induced complications (odema and inflammation) make an ideal choice for their use in different therapeutics (Shibuya, 2009).

VEGFR1: also termed as FMS-like tyrosine kinase (FLT) is localized on 13q12. It encoding region contain 15 exons with a protein size of $150.6 \mathrm{kDa}$. It encompasses 1,338-amino acids. It is expressed in placenta, liver, muscle, and kidney.

VEGFR2: It belongs to tyrosine kinase family and also named as FLK with localized region identified at $4 q 12$. It comprises of 30 exons encoding a protein of 1356 amino acids. A splice variant of VEGFR2 has been observed in RT-PCR analysis of human umbilical vein endothelial cells. In frame retention of intron 13 containing an in-frame termination codon have been reported. This truncated protein retains a unique 16 amino acids out of 679 amino acids content at C-terminal sequence (Albuquerque et al., 2009).

VEGFR3: It is also termed as FMS like tyrosine kinase 4 (FLT4) which has been identified on 5q34-35 encompassing 30 exons. Two isoforms of this molecule 
Syeda Kiran Riaz et al

has been categorized with amino acid variation of 1363 and 1298 respectively. Its association in lymphatic metastasis has quite recently been explored in head and neck cancer (Wang et al., 2012).

\section{Involvement of VEGFs in Different Cancer Types}

\section{Effect of VEGFA in cancer}

Expressional dysregulation of VEGFA has been observed in different cancers. Interestingly, up-regulation of VEGFA is also associated with lethal hepatic syndrome (Chen et al., 2014), gastric (Liu et al., 2011), lungs (Jin et al., 2011; Zhang et al., 2014), ovarian (Khemapech et al., 2012) pancreatic (Tang et al., 2006) head and neck (Srivastava et al., 2014), thyroid papillary carcinoma (Klein et al., 2001), myeloid tumors (Stockman et al., 2008; Kim et al., 2009), breast cancer (Schneider et al., 2010; Zhang et al., 2013), medulloblastoma (Pereira et al., 2010), osteosarcoma (Zhu et al., 2010), bladder (Chen et al., 2012; Pignot et al., 2009), colorectal cancer (Sheffer et al., 2009) myeloma (Vlajnic et al., 2010) and glioblastoma (Hose et al., 2009). Although no significant association of VEGF with hormone receptors (ER, PR and HER status) has been established, yet a strong prognostic correlation in relation to mammary, prostate, hepatic, head and neck tumors had been established (Ryden et al., 2005; Yu et al., 2010; Wang et al., 2012; Xu et al., 2013; Srivastava et al., 2014). Hence a consistent finding of VEGFA over expression in majority of cancer strongly suggests it prognostic significance when analyzed with other markers.

\section{Effect of VEGFB in cancer}

Association of VEGFB in relation to diabetes, cardiovascular complications, Parkinson disease and obesity are very well established in the literature (Falk et al., 2009). However, effect of VEGFB on different cancer progression is still an area that requires further investigations. Fauconnet (2009) observed a significant association of VEGFA with bladder cancer while no salient association VEGFB was observed. VEGFB expressional dysregulation has been reported in hepatic cellular carcinoma, breast cancer nodal metastasis and invasiveness (Mylona et al., 2007; Kanda et al., 2008). Evaluation of VEGFB as a prognostic marker requires further validation on large cohort samples.

\section{Effect of VEGFC in cancer}

Increased expression of VEGFC in bladder (Suzuki et al., 2005), gastric (Kabashima et al., 2001) pancreatic (Sipos et al., 2004), colon (Furudoi et al., 2002), prostate (Qi et al., 2014) and cervical (Fujimoto et al., 2004; Mitsuhashi et al., 2005) had also been observed. A direct correlation of VEGFC with COX2 has also been established in earlier published reports (Byeon et al., 2004; Su et al., 2004; Kyzas et al., 2005). Earlier in 2004, Lee (2004) a strong impact of COX2 in cervical cancer angiogenesis had been established. Hence, VEGF-C is suggested as downstream effectors of COX2 in relation to cancer proliferation as observed in vivo assays and breast cancer cells invasion. A

\section{Effect of VEGFD in Cancer}

Metastasis promotion in relation to lymphatic vessels involvement has been correlated with VEGFD expression. It triggers lymphatic nodules formation ultimately leading to angiogenesis and tumor growth. VEGF-D over expression at both protein and mRNA level have been observed in colorectal, prostate, breast and endometrial cancer (Yokoyama et al., 2003; Coen et al., 2005; Van Iterson et al., 2007; Zhang et al., 2010). Over expression of VEGFC and VEGFD also led to neoformation of lymphatic vessels in gastric tumor cell lines (Yonemura et al., 2005). In another study, although no association of VEGFC with clinical or histopathological parameters of bladder cancer patients has been observed, but a significant correlation of VEGFD had been established. Interestingly, a full length of VEGFD molecule is unable to induce angiogenesis while proteolytic cleaving fragments of VEGFD fragment is mainly thought to be responsible for metastasis progression and angiogenesis (McColl et al., 2007).

\section{Effect of VEGFRI in cancer}

Inverse correlation of VGEFR 1 and sFLT-1 was observed on clinical onset of preeclampsia when compared with serum levels of other woman belonging to same age group retaining a normal gestation (Levine et al., 2004). Similarly, both VEGFA and VEGFR1 increased expression had also been associated with choroidal neovascularization resulting in age related macular degeneration. In a quite recent report, genetic variation of VEGFA and VEGFR1 was also found to be increase risk towards breast and lung cancer susceptibility (Beeghly-Fadiel et al., 2011; Cao et al., 2013).

\section{Effect of VEGFR2 in cancer}

Increased VEGFR2 expression has been observed in induced hypoxia among breast cancer and retinal neovascularization ( $\mathrm{Li}$ et al., 2014). Similarly, frequent aberrations on the genomic portion of VEFR2 have also been observed in hemangiomas (Walter et al., 2002). A novel approach regarding TIMP3 inducing blockade of VGEF mediated inhibition also led to fundus dystrophy (Qi et al., 2003).

\section{Effect of VEGFR3 in cancer}

VEGFR3 mutations were extensively been observed in patients of a relative less common tumor lymphedema type IA (Ghalamkarpour et al., 2006). Its over expression has strongly been correlated with lymphatic metastasis among head and neck cancer patients.

Further studies regarding role of these receptors in regulating cancer progression and metastasis are required. Molecular cross talks of the receptors not only with VEGFs but also with other proteins increase their functional diversity in tumor vasculature. The main focus of the current therapeutic regimes is to impair tumor persistent growth and pervasiveness into the surrounding environment. VEGF based therapeutic approaches cover a range of different molecules which may be able to impede molecular signaling at different levels of the VEGF pathway. 
Table 1. Clinical Correlation of VEGF Molecules with Different Types of Cancer

\begin{tabular}{|l|l|l|}
\hline Molecules & Types of Cancer & Expressional Regulation \\
\hline VEGFA & $\begin{array}{l}\text { Gastric, Lungs, Ovarian, Pancreatic, Head and Neck, } \\
\text { Breast, Bladder, Colorectal cancer, Thyroid papillary } \\
\text { carcinoma, Myeloid tumors, Medulloblastoma, Osteosar- } \\
\text { coma, Myeloma and Glioblastoma }\end{array}$ & $\begin{array}{l}\text { Increase expression with poor disease over all } \\
\text { survival and tumor progression }\end{array}$ \\
\hline VEGFB & $\begin{array}{l}\text { Lung cancer progression, Hepatic cellular carcinoma, } \\
\text { Breast cancer nodal metastasis and invasiveness }\end{array}$ & Expression yet to be ascertained in large cohorts \\
\hline VEGFC & $\begin{array}{l}\text { Squamous cell carcinoma of the cervix, Bladder Gastric, } \\
\text { Pancreatic Colon and Prostate Cancer }\end{array}$ & Increase expression with poor outcome \\
\hline VEGFD & $\begin{array}{l}\text { Colorectal, Prostate, Breast, Endometrial, Gastric and } \\
\text { Bladder Cancer }\end{array}$ & Increased expression of protein and mRNA as \\
well
\end{tabular}

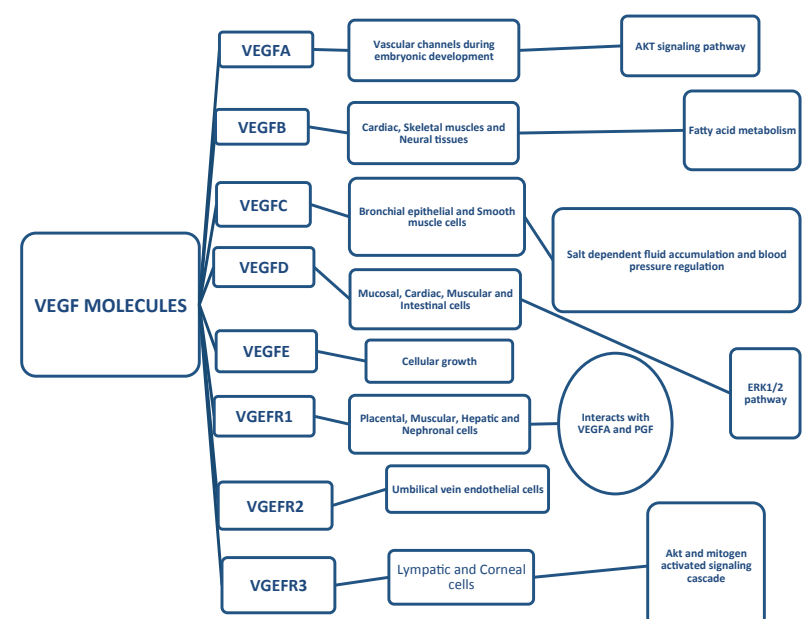

Figure 1. VEGF Members and their Expression in Endothelial Cells

\section{Therapeutic Implications of VEGF Inhibitors}

Over expression of COX-2 resulted in increased angiogenic stimulation and tumor proliferation. Celecoxib (drug selective for COX-2 inhibition) expression plays a pivotal role in suppression of angiogenesis. Its potential benefits in hepatocellular carcinoma (HCC) patients have been observed. Marked reduction in seroangiogenic factors (VEGFs) had been observed after a combinatorial administration of bevacizumab along with 5-fluorouraci (5FU) and cyclophosphamide (endoxan) (Bassiouny et al., 2010).

\section{Targeting VEGF Molecule (Avastin)}

A monoclonal antibody Bevacizumab (Avastin ${ }^{\circledR}$; Genentech, Inc., South San Francisco, CA) specifically target VEGFA expression. Earlier, it showed showed increase colon cancer patients survival over conventional chemotherapeutics medicines (Los et al., 2007). This compound is found responsible for regression of tumor vasculature, inhibition of new vessels formation and even blockade of progenitor cells from bone marrow (Wood et al., 2000; Willett et al., 2004). FDA recommends this drug against colon, kidney, brain, and lung cancers cases however it was not suggested for breast cancer affected patients as more complications are introduced in this regard (FDA recommendations 2010). One possible reason of reduced efficiency in late breast cancer affected patients is because of wide molecular cross talks responsible for angiogenic induction. Hence alternative substitute for angiogenic suppression are required.

\section{Targeting VEGF Receptors (Semaxanib SU 5416, SU 6668)}

Tyrosine kinase inhibitors have been used to target VEGFR by introducing autophosphorylation. Semaxanib (SU5416) drug was found very effective against Kaposi's sarcoma and advanced stage malignancies (Mendel et al., 2000). However, it side effects leading to suppression of lymphocyte germination and immune response stop their further usage (Grailer and Steeber, 2013). Another drug of choice namely su6668 from Sugen pharmaceuticals designed competitively against VEGFR is also withdrawn due to quite similar findings (Lee et al., 2001). FLJ10540 blockage mediated by VEGFR 2 or PI3K inhibitors results in halt of VEGF and Akt pathway expression of lung cancer cells invasion and migration (Liu et al., 2010). Vatalanib (PTK787/ZK 222584) is a small molecule tyrosine kinase inhibitor against VEGFR-1 to -3. TK787/ ZK 222584 might have more clinical potential in AML when combined with a chemotherapeutic drug such as amsacrine. In future, it will be interesting to study whether the complications and the long-term effects of chemotherapy can be reduced by lowering the dosages of amsacrine, and by replacing it with other drugs with lower toxicity profiles, such as PTK787/ZK 222584 (Weidenaar et al., 2008), TGF $\beta$ RII significantly inhibits tumor progression and also resulted in loss of VEGFA expression. TGF $\beta$ RII also inhibit ascites formation and improve ascites drainage (Liao et al., 2011). Similarly AEE788 also showed a wide spectrum efficiency by inhibiting expression of epidermal growth factors receptors as well as VEGFRs in medulloblastoma established cell lines (Meco et al., 2010). Serious AEs, most commonly grade 3/4 liver function test elevations, were responsible for treatment discontinuation in $17 \%$ of patients. AEE788 concentrations were reduced by EIACD. The best overall response was stable disease (17\%) (Reardon et al., 2012). 


\section{Conclusion and Future Prospectives}

VEGF molecules increase vascular permeability, cell growth, cell migration, and inhibit apoptosis. Role of VEGF-A is of clear prognostic importance and is targeted by monoclonal antibody based product Bevacizumab. Better insights of pathways underlying the involvement of other VEGFs mediated regulation is an important avenue to explore. Many drugs are being tested clinically in this regard and future studies targeting both VEGFs and VEGFRs in order to develop therapeutics will proof efficient in reducing the complications of chemotherapy in various types of cancers.

\section{Acknowledgements}

We would like to thank and acknowledge HEC and COMSATS-IT for their support.

\section{References}

Albuquerque RJC, Hayashi T, Cho WG, et al (2009). Alternatively spliced vascular endothelial growth factor receptor-2 is an essential endogenous inhibitor of lymphatic vessel growth. Nature Med, 15, 1023-30.

Bassiouny AR, Zaky A, Neenaa HM (2010). Synergistic effect of celecoxib on 5-fluorouracil-induced apoptosis in hepatocellular carcinoma patients. Ann Hepatol, 1, 410-8.

Beeghly-Fadiel A, Shu XO, Lu W, et al (2011). Genetic variation in VEGF family genes and breast cancer risk: a report from the Shanghai breast cancer genetics study. Cancer Epidemiol Biomarkers Prev, 20, 33-41.

Byeon JS, Jung HY, Lee YJ, et al (2004). Clinicopathological significance of vascular endothelial growth factor-C and cyclooxygenase- 2 in esophageal squamous cell carcinoma. J Gastroenterol Hepatol, 19, 648-654.

Cao C, Sun SF, Lv D, et al (2013). Utility of VEGF and sVEGFR-1 in bronchoalveolar lavage fluid for differential diagnosis of primary lung cancer. Asian Pac J Cancer Prev, 14, 2443-6.

Chen JD, Xiong YQ, Dong K, et al (2014). Clinical significance of joint detection of serum VEGF, SIL-2R and HGF in patients with primary hepatocellular carcinoma before and after percutaneous microwave coagulation therapy. Asian Pac J Cancer Prev, 15, 4545-8.

Chen JX, Deng N, Chen X, et al (2012). A novel molecular grading model: combination of Ki67 and VEGF in predicting tumor recurrence and progression in non-invasive urothelial bladder cancer. Asian Pac J Cancer Prev, 13, 2229-34.

Coen J, Bermudez S, Suzuki Y, et al (2005). VEGF-D expression predicts biochemical outcome in localized prostate cancer treated with external radiation: a ten-year cohort analysis. J Clin Oncol, 23, 16.

Donnemab T, Al-Shiblicd K, Al-Saadce S, et al (2009). VEGF-A and VEGFR-3 correlate with nodal status in operable non-small cell lung cancer: inverse correlation between expression in tumor and stromal cells. Lung Cancer, 63, 277-83.

Falk T, Zhang S, Sherman SJ (2009). Vascular endothelial growth factor B (VEGF-B) is up-regulated and exogenous VEGF-B is neuroprotective in a culture model of Parkinson's disease. Mol Neurodegener, 10, 49.

Fauconnet S, Bernardini S, Lascombe I, et al (2009). Expression analysis of VEGF-A and VEGF-B: relationship with clinicopathological parameters in bladder cancer. Oncol
Rep, 21, 1495-504.

Fujimoto J, Toyoki H, Sato E, Sakaguchi H, Tamaya T (2004). Clinical implication of expression of vascular endothelial growth factor-C in metastatic lymph nodes of uterine cervical cancers. Br J Cancer, 91, 466-69.

Furudoi A, Tanaka S, Haruma K, et al (2002). Clinical significance of vascular endothelial growth factor $\mathrm{C}$ expression and angiogenesis at the deepest invasive site of advanced colorectal carcinoma. Oncology, 62, 157-66.

Ghalamkarpour A, Morlot S, Raas-Rothschild A, et al (2006). Hereditary lymphedema type I associated with VEGFR3 mutation: the first de novo case and atypical presentations. Clin Genet, 70, 330-5.

Grailer JJ, Steeber DA (2013). Vascular endothelial growth factor receptor inhibitor SU5416 suppresses lymphocyte generation and immune responses in mice by increasing plasma corticosterone. PLOS ONE, 8, 75390.

Hose D, Moreaux J, Meissner T, et al (2009). Induction of angiogenesis by normal and malignant plasma cells. Blood, 114, 128-43.

Jin Y, Li JP, Tang LY, et al (2011). Expression and significance of VEGF, EGFR and MMP-9 in non-small cell lung carcinomas. Asian Pac J Cancer Prev, 12, 1473-6.

Kabashima A, Maehara Y, Kakeji Y, Sugimachi K (2001). Overexpression of vascular endothelial growth factor $\mathrm{C}$ is related to lymphogenous metastasis in early gastric carcinoma. Oncology, 60, 146-50.

Kanda M, Nomoto S, Nishikawa Y, et al (2008). Correlations of the expression of vascular endothelial growth factor B and its isoforms in hepatocellular carcinoma with clinicopathological parameters. Surg Oncol, 98, 190-6.

Khemapech N, Pitchaiprasert S, Triratanachat S (2012). Prevalence and clinical significance of mammalian target of rapamycin phosphorylation (p-mTOR) and vascular endothelial growth factor (VEGF) in clear cell carcinoma of the ovary. Asian Pac J Cancer Prev, 13, 6357-62.

Kim DH, Xu W, Ma C, et al (2009). Genetic variants in the candidate genes of the apoptosis pathway and susceptibility to chronic myeloid leukemia. Blood, 113, 2517-25.

Klein M, Vignaud JM, Hennequin V, et al (2001). Increased expression of the vascular endothelial growth factor is a pejorative prognosis marker in papillary thyroid carcinoma. $J$ Clin Endocrinol Metab, 86, 656-8.

Kyzas PA, Stefanou D, Agnantis NJ (2005). COX-2 expression correlates with VEGF-C and lymph node metastases in patients with head and neck squamous cell carcinoma. Mod Pathol, 18, 153-60.

Lee JS, Choi YD, Lee JH, et al (2004). Expression of cyclooxygenase- 2 in adenocarcinomas of the uterine cervix and its relation to angiogenesis and tumor growth. Gynecol Oncol, 95, 523-9.

Lee S. Rosen, et al (2001). Phase I experience with SU6668, a novel multiple receptor tyrosine kinase inhibitor in patients with advanced malignancies. Proc Am Soc Clin Oncol, 20.

Levine RJ, Maynard SE, Qian C, et al (2004). Circulating angiogenic factors and the risk of preeclampsia. New Eng $J$ Med, 350, 672-683.

Li X, Aase K, Li H, von Euler G, Eriksson U (2001). Isoformspecific expression of VEGF-B in normal tissues and tumors. Growth Factors, 19, 49-59.

Li YP, TianFG, Shi PC, et al (2014). 4-Hydroxynonenal promotes growth and angiogenesis of breast cancer cells through HIF$1 \alpha$ stabilization. Asian Pac J Cancer Prev, 15, 10151-6.

Liao S, Liu J, Lin P, (2011). TGF-\{beta\} blockade controls ascites by preventing abnormalization of lymphatic vessels in orthotopic human ovarian carcinoma models. Clin Cancer Res, 17, 1415-24. 
Liu BY, Soloviev I, Chang P, et al (2010). Stromal cell-derived factor-1/CXCL12 contributes to MMTV-Wnt1 tumor growth involving Gr1+CD11b+ cells. PLoS One, 5, 8611 .

Liu H, Wang S, Huang C (2011). VEGFA+936C/T and -634G/C polymorphisms and gastric cancer risk: a meta-analysis. Asian Pac J Cancer Prev, 12, 1979-83.

Los M, Roodhart JML, Voest EE (2007). Target practice: lessons from phase III trials with bevacizumab and vatalanib in the treatment of advanced colorectal cancer. Oncologist, 1, 443-50.

McColl BK, Paavonen K, Karnezis T, et al (2007). Proprotein convertases promote processing of VEGF-D, a critical step for binding the angiogenic receptor VEGFR-2. FASEB $J$, 21, 1088-98.

Meco D, Servidei T, Zannoni GF, et al (2010). Dual inhibitor AEE788 reduces tumor growth in preclinical models of medulloblastoma. Transl Oncol, 3, 326-35.

Meiron M, Anunu R, Scheinman EJ, Hashmueli S, Levi BZ (2001). New isoforms of VEGF are translated from alternative initiation CUG codons located in its 5'UTR. Biochem Biophys Res Commun, 282, 1053-60.

Mendel DB, Schreck RE, West DC, et al (2000). The angiogenesis inhibitor SU5416 has long-lasting effects on vascular endothelial growth factor receptor phosphorylation and function. Clin Cancer Res, 12, 4848-58.

Millauer B, Wizigmann-Voos S, Schnurch H, et al (1993). High affinity VEGF binding and developmental expression suggest Flk-1 as a major regulator of vasculogenesis and angiogenesis. Cell, 72, 835-46.

Mitsuhashi A, Suzuka K, Yamazawa K, et al (2005). Serum vascular endothelial growth factor (VEGF) and VEGF-C levels as tumor markers in patients with cervical carcinoma. Cancer, 103, 724-30.

Mylona E, Alexandrou P, Giannopoulou I et al (2007). The prognostic value of vascular endothelial growth factors (VEGFs)-A and -B and their receptor, VEGFR-1, in invasive breast carcinoma. Gynecol Oncol, 104, 557-63.

Nilsson I, Bahram F, Li X, Gualandi L, et al (2010). VEGF receptor $2 /-3$ heterodimers detected in situ by proximity ligation on angiogenic sprouts. EMBO J, 29, 1377-8.

Pereira ER, Liao N, Neale GA, Hendershot LM (2010). Transcriptional and post-transcriptional regulation of proangiogenic factors by the unfolded protein response. PLoS One, 5, 12521.

Pignot G, Bieche I, Vacher S, et al (2009). Large-scale real-time reverse transcription-PCR approach of angiogenic pathways in human transitional cell carcinoma of the bladder: identification of VEGFA as a major independent prognostic marker. Eur Urol, 56, 678-88.

Qi JH, Ebrahem Q, Moore N, et al (2003). A novel function for tissue inhibitor of metalloproteinases-3 (TIMP3): inhibition of angiogenesis by blockage of VEGF binding to VEGF receptor-2. Nat Med, 9, 407-15.

Qi WX, Fu S, Zhang Q, et al (2014). Efficacy and toxicity of antiVEGF agents in patients with castration-resistant prostate cancer: a meta-analysis of prospective clinical studies. Asian Pac J Cancer Prev, 15, 8177-82.

Reardon DA, Conrad CA, Cloughesy T, et al (2012). Phase I study of AEE788, a novel multitarget inhibitor of ErbBand VEGF-receptor-family tyrosine kinases, in recurrent glioblastoma patients. Cancer Chemotherapy Pharmacol, 69, 1507-18.

Ryden L, Stendahl M, Jonsson H, et al (2005). Tumor-specific VEGF-A and VEGFR2 in postmenopausal breast cancer patients with long-term follow-up. Implication of a link between VEGF pathway and tamoxifen response. Breast Cancer Res Treat, 89, 135-43.
Schneider BP, Radovich M, Hancock BA, et al (2010). VEGFA amplification/deletion in human breast tumors. J Clin Oncol, 28, 15.

Shariat SF (2009). Editorial comment on: large-scale real-time reverse transcription-PCR approach of angiogenic pathways in human transitional cell carcinoma of the bladder: identification of VEGFA as a major independent prognostic marker. European Urology, 56, 688-9.

Sheffer M, Bacolod MD, Zuk O, et al (2009). Association of survival and disease progression with chromosomal instability: a genomic exploration of colorectal cancer. Proc Natl Acad Sci USA, 106, 7131-6.

Shibuya M (2009). Unique signal transduction of the VEGF family members VEGF-A and VEGF-E. Biochem Soc Trans, 37, 1161-6.

Sipos B, Klapper W, Kruse ML, et al (2004). Expression of lymphangiogenic factors and evidence of intratumoral lymphangiogenesis in pancreatic endocrine tumors. $\mathrm{Am} \mathrm{J}$ Pathol, 165, 1187-97.

Srivastava VK, Gara RK, Rastogi N, et al (2014). Serum vascular endothelial growth factor-A (VEGF-A) as a biomarker in squamous cell carcinoma of head and neck patients undergoing chemoradiotherapy. Asian Pac J Cancer Prev, 15, 3261-5.

Stockmann C, Doedens A, Weidemann A, et al (2008). Deletion of vascular endothelial growth factor in myeloid cells accelerates tumorigenesis. Nature, 456, 814-8.

Su JL, Shih JY, Yen ML, et al (2004). Cyclooxygenase-2 induces EP1- and HER-2/Neu-dependent vascular endothelial growth factor-C up-regulation: a novel mechanism of lymphangiogenesis in lung adenocarcinoma. Cancer Res, 64, 554-64.

Tang RF, Wang SX, Peng L, et al (2006). Expression of vascular endothelial growth factors $\mathrm{A}$ and $\mathrm{C}$ in human pancreatic cancer. World J Gastroenterol, 12, 280-6.

Van Iterson V, Leidenius M, von Smitten K, Bono P, Heikkila $P$ (2007). VEGF-D in association with VEGFR-3 promotes nodal metastasis in human invasive lobular breast cancer. Am J Clin Pathol, 128, 759-66.

Vlajnic T, Zlobec I, Karamitopoulou E (2010). VEGFA amplification correlates with adverse outcome in colorectal cancer. Virchows Archiv, 457, 226-7.

Walter JW, North PE, Waner M, et al (2002). Somatic mutation of vascular endothelial growth factor receptors in juvenile hemangioma. Genes Chromosomes Cancer, 33, 295-303.

Wang K, Peng HL, Li LK (2012). Prognostic value of vascular endothelial growth factor expression in patients with prostate cancer a systematic review with meta-analysis. Asian Pac J Cancer Prev, 13, 5665-9.

Wang Z, Chen Y, Li X, et al (2012). Expression of VEGF-C/ VEGFR-3 in human laryngeal squamous cell carcinomas and its significance for lymphatic metastasis. Asian Pac J Cancer Prev, 13, 27-31.

Weidenaar AC, de Jonge HJ, Fidler V, et al (2008). Addition of PTK787/ZK 222584 can lower the dosage of amsacrine to achieve equal amounts of acute myeloid leukemia cell death. Anticancer Drugs, 19, 45-54.

Willett CG, Boucher Y, di Tomaso E, et al (2004). Direct evidence that the VEGF-specific antibody bevacizumab has antivascular effects in human rectal cancer. Nat Med, 10, 145-7.

Wood JM, Bold G, Buchdunger E, et al (2000). PTK787/ZK 222584 , a novel and potent inhibitor of vascular endothelial growth factor receptor tyrosine kinases, impairs vascular endothelial growth factor-induced responses and tumor growth after oral administration. Cancer Res, 60, 2178-89.

Xu N, Lei Z, Li XL, et al (2013). Clinical study of tumor 
angiogenesis and perfusion imaging using multisplice spiral computed tomography for breast cancer. Asian Pac J Cancer Prev, 14, 429-33.

Yokoyama Y, Charnock-Jones DS, Licence D, et al (2003). Expression of vascular endothelial growth factor (VEGF)-D and its receptor, VEGF receptor 3 , as a prognostic factor in endometrial carcinoma. Clin Cancer Res, 4, 1361-9.

Yonemura Y, Endo Y, Tabata K, et al (2005). Role of VEGF-C and VEGF-D in lymphangiogenesis in gastric cancer. Int $J$ Clin Oncol, 10, 318-27.

Yu DC, Chen J, Ding YT (2010). Hypoxic and highly angiogenic non-tumor tissues surrounding hepatocellular carcinoma: the 'niche' of endothelial progenitor cells. Int J Mol Sci, 11, 2901-9.

Zhang SJ, Hu Y, Qian HL, et al (2013). Expression and Significance of ER, PR, VEGF, CA15-3, CA125 and CEA in judging the prognosis of breast cancer. Asian Pac J Cancer Prev, 14, 3937-40.

Zhang Y, Yu LK, Lu GJ, et al (2014). Prognostic values of VEGF and endostatin with malignant pleural effusions in patients with lung cancer. Asian Pac J Cancer Prev, 15, 8435-40.

Zhu XZ, Yin HM, Mei J (2010). Inhibition of tumors cell growth in osteosarcoma-bearing SD rats through a combination of conventional and metronomic scheduling of neoadjuvant chemotherapy. Acta Pharmacol Sin, 31, 970-6. 